\title{
Population structure and coil dimorphism in a tropical land snail
}

\author{
M Schilthuizen ${ }^{1}$, BJ Scott ${ }^{2}$, AS Cabanban ${ }^{3}$ and PG Craze ${ }^{4}$ \\ ${ }^{1}$ Institute for Tropical Biology and Conservation, Universiti Malaysia Sabah, Kota Kinabalu, Malaysia; ${ }^{2}$ Faculty of Science, Engineering \\ and Technology, Victoria University, Melbourne, Victoria, Australia; ${ }^{3}$ Borneo Marine Research Institute, Universiti Malaysia Sabah, \\ Kota Kinabalu, Malaysia; ${ }^{4}$ Department of Biological Sciences, University of Plymouth, Plymouth, UK
}

\begin{abstract}
Tree snails of the subgenus Amphidromus s. str. are unusual because of the chiral dimorphism that exists in many species, with clockwise (dextrally) and counter-clockwise (sinistrally) coiled individuals co-occurring in the same population. Given that mating in snails is normally impeded when the two partners have opposite coil, positive frequencydependent selection should prevent such dimorphism from persisting. We test the hypothesis that a strong population structure with little movement between tree-based demes may result in the fixation of coiling morphs at a very small spatial scale, but apparent dimorphism at all larger scales. To do so, we describe the spatial structure in a Malaysian population of $A$. inversus (Müller, 1774) with $36 \%$ dextrals.
\end{abstract}

We marked almost 700 juvenile and adult snails in a piece of forest consisting of 92 separate trees, and recorded dispersal and the proportions of dextrals and sinistrals in all trees over a 7-day period. We observed frequent movement between trees (155 events), and found that no trees had snail populations with proportions of dextrals and sinistrals that were significantly different from random. Upon recapture 1 year later, almost two-thirds of the snails had moved away from their original tree. We conclude that population structure alone cannot stabilise the coil dimorphism in Amphidromus. Heredity (2005) 95, 216-220. doi:10.1038/sj.hdy.6800715; published online 3 August 2005

Keywords: gene flow; frequency-dependent selection; fixation; chirality; Camaenidae

\section{Introduction}

The coiled body plan of pulmonate snails (Mollusca: Gastropoda Pulmonata) allows for entire-body dimorphism, with individuals coiled either clockwise (dextral; D), or counter-clockwise (sinistral; S). Studies on phylogenetically unrelated species (Degner, 1952; Murray and Clarke, 1976; Freeman and Lundelius, 1982) suggest that coiling direction is normally determined by the maternal genotype at a single locus, with genetic dominance of either the dextral or the sinistral allele (van Batenburg and Gittenberger, 1996). Most pulmonate species, however, are uniform in coiling, with reverse-coiled individuals only appearing as rare mutants (Gittenberger, 1988). Such mutants usually will experience positive frequency-dependent selection. This is due to the fact that during mating between individuals with opposite coil, successful contact between the genital openings (located on the right-hand side of the body in a dextral, on the left-hand side of the body in a sinistral snail) is impeded: hindrance is particularly severe in snails with globular shells, but also, to a lesser extent, in high-spired ones (Asami et al, 1998). Computer simulations and field observations confirm that only in rare cases does a sinistral population become established within a dextral species or vice versa (Johnson et al, 1990; Orr, 1991; van

Correspondence: M Schilthuizen, Institute for Tropical Biology and Conservation, Universiti Malaysia Sabah, Locked Bag 2073, 88999 Kota Kinabalu, Malaysia. E-mail: schilthuizen@yahoo.com

Received 8 February 2005; accepted 14 June 2005; published online 3 August 2005
Batenburg and Gittenberger, 1996; Stone and Björklund, 2002; Ueshima and Asami, 2003).

However, certain pulmonate species exist that are dimorphic for coiling direction. Asami (1993) mentions 11 genera in which such dimorphism occurs, although in most of these it is either restricted to certain populations or it is present only in a hybrid zone between a dextral and a sinistral population (viz. Partula suturalis; Johnson, 1982). Pervasive, stable dimorphism is very rare indeed and may be restricted to just a few groups. Probably the best known of these is the tropical tree snail Amphidromus s. str. (Camaenidae). A total of 36 species are currently included in this subgenus, of which 28 are dimorphic, one sinistral, and four dextral; for the remaining three, coiling direction is not known (data compiled from Laidlaw and Solem, 1961; Panha, 1996; Lehmann and Maassen, 2004; W Maassen, personal communication, and T Asami, personal communication). Observations on several dimorphic Amphidromus species from Indonesia, Malaysia, Singapore, and Thailand (PGC, MS, S Panha, JJ Vermeulen, unpublished data) suggest that dextrals and sinistrals usually occur in roughly equal proportions within local populations.

Details on Amphidromus mating behaviour are not available yet, but given the knowledge for other species, including ones with similar shell shape, like Partula (Johnson, 1982), it is probable that Amphidromus pairs of opposite coil will also experience some difficulty in mating compared with pairs of the same coiling direction. The widespread dimorphism in Amphidromus is therefore surprising (Gittenberger, 1988; Asami et al, 1998), since any deviation from equal proportions will 
give a selective disadvantage to the rarer morph, leading to fixation of the commoner morph, especially if this morph is the genetically dominant one ('dominance drive,' Mallet, 1986). Computer simulations (van Batenburg and Gittenberger, 1996) show that stable dimorphism is not expected to persist unless a balancing process is at work.

Several such balancing processes may be envisaged in Amphidromus. First, the positive frequency-dependent selection against the rarer morph could be counteracted by a negative environmental frequency-dependent selection. For example, predators may set their search image or their routine way of prey-handling by the most common morph, giving a reduced predation pressure to the rarer morph (Ayala and Campbell, 1974). However, this and other explanations, such as heterosis or hitchhiking (Laidlaw and Solem, 1961) are not likely to be simultaneously applicable to almost 30 species inhabiting a variety of habitats in a region spanning a large part of South and Southeast Asia.

An alternative explanation may lie in Amphidromus' population structure. These tree-dwelling animals are almost never found at ground level and probably spend most of their lives on the trunks and branches of trees (MS and PGC, unpublished observations). Possibly, like in many other land snails (Murray and Clarke, 1984; Schilthuizen and Lombaerts, 1994; Pfenninger et al, 1996; Giokas and Mylonas, 2004), strongly structured populations exist with very little dispersal between neighbouring demes. This metapopulation structure may result in the fixation of either coiling morph in tree-sized demes, resulting in bimodal distributions of morph proportions at the scale of single trees, but apparent random cooccurrence of both morphs on a slightly larger spatial scale. In this paper, we examine this possible explanation for stable dimorphism by studying population structure in one dimorphic species, A. inversus from Malaysia.

\section{Materials and methods}

\section{Study species and locality}

A. inversus (Müller, 1774) is a widespread, chirally dimorphic species (Figure 1), ranging from Annam in the west to Sulawesi in the east. It has a mottled-white shell that is approximately $4 \mathrm{~cm}$ tall and $2 \mathrm{~cm}$ wide. As in all camaenids, the shell peristome folds like a lip upon reaching sexual maturity. During surveys in 1989 and 1997, one of us (MS) found a dense population of this species in primary and secondary forest on the 2-kmlong island of Kapas, off the east coast of Peninsular Malaysia (approximately $103^{\circ} 16^{\prime}$ E $5^{\circ} 12^{\prime} \mathrm{N}$ ). We studied this population from 29 August until 7 September 2003 and again from 26 to 31 August 2004. We selected a representative $40 \times 100 \mathrm{~m}$ section of coastal forest on sandy soil, and numbered, mapped, and estimated the crown sizes of all 92 trees within this section (Figure 2).

\section{Marking and recapturing snails}

We gave all snails less than $2.5 \mathrm{~m}$ above the ground a pencil mark at the outside of the palatal wall of the aperture and recorded the trees they were on for 7 consecutive days. The mark consisted of a symbol representing the day on which the snail was marked, and a number indicating the tree on which it was found. All marks remained legible throughout the study period.

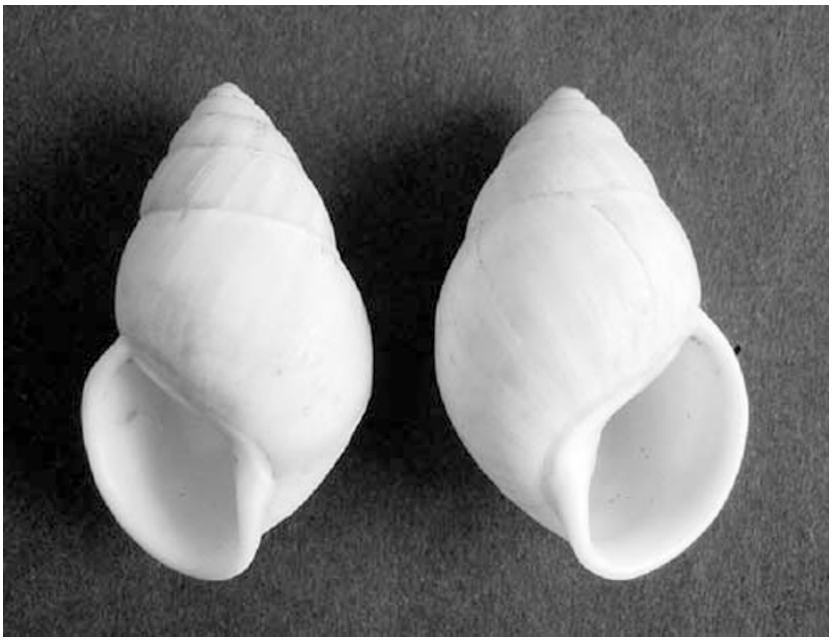

Figure 1 A sinistral (left) and a dextral (right) shell of A. inversus from the island of Kapas, Malaysia. Shell height is approximately $4 \mathrm{~m}$. (The dissimilarity in shell shape is accidental.)

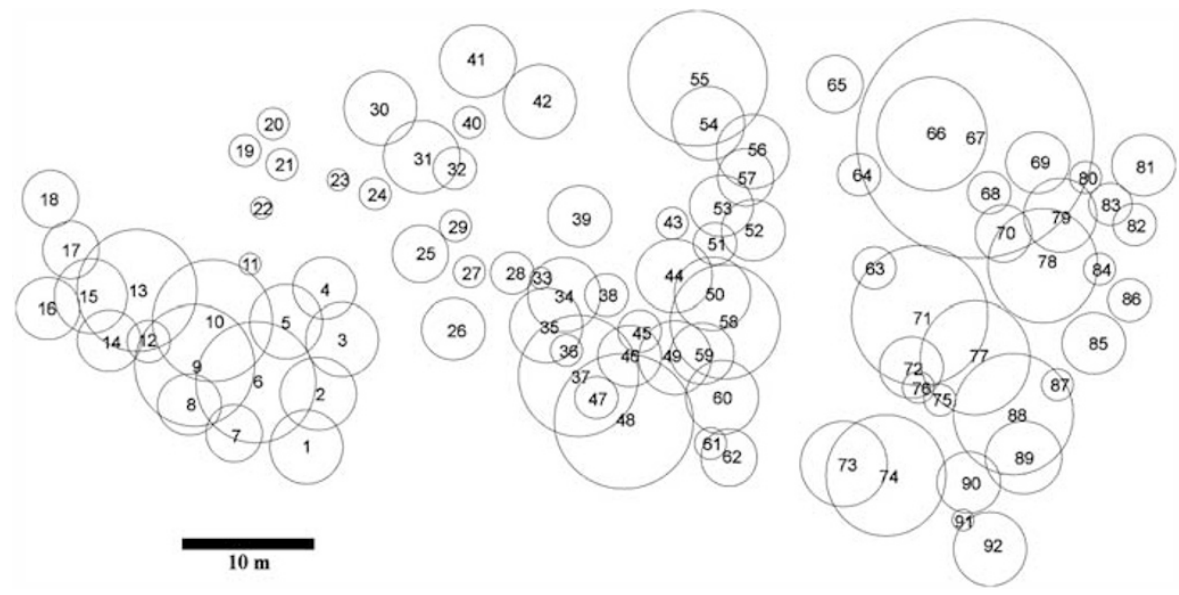

Figure 2 Map of the $40 \times 100$ m study site, with all 92 trees and their crown sizes indicated. 
Mostly, marking was done without removing the animals from their substrate. For each snail, we recorded its morph (D or S) and age (juvenile or adult). Whenever we found a marked snail that derived from a different tree than where it was found, we recorded its original tree and gave it an additional mark for its current tree. After 1 year, the same locality was revisited. All trees were searched twice for $2.5 \mathrm{~h}$ within a 2-day interval. The positions of all living individuals that still had readable markings were recorded.

\section{Morph frequencies and clustering}

We determined morph frequencies in the contemporary population from all marked individuals in the 2003 field season. In addition, we collected samples of old, weathered shells from the forest floor to determine morph frequencies in previous generations. For each tree, we took a census of the snail population present on day 7 , based on all individuals marked throughout days 1-7 plus immigrants, minus emigrants, minus deaths (ie, marked snails found dead). We then calculated the proportions of dextrals and sinistrals for each tree and tested these against expected proportions using twotailed binomial tests, provided the total number was 10 or larger. We applied sequential Bonferroni correction (Holm, 1979) to account for multiple tests.

\section{Results}

Over all 7 days, we collected and marked 695 living snails: 268 adults and 427 juveniles. Of these, 250 (36\%) were dextral (A survey at $1 \mathrm{~km}$ distance (MS, unpublished data) gave 76 out of 220 dextrals, suggesting that this percentage is more or less constant throughout the island.) The empty, weathered shells that we collected in the same section of forest consisted of 73 dextral and 124 sinistral snails, giving a very similar proportion of dextrals during previous generations of $37 \%$ (voucher specimens from this sample are available in the BORNEENSIS collection of Universiti Malaysia Sabah under reference number BOR/MOL/2964). Although our data do not allow for formal estimation of population size (Begon, 1979), visual extrapolation of the cumulative numbers of marked adult individuals (for days 1 through 7 , respectively: $60,110,152,177,205,245$, and 268) suggests that the asymptote for the total adult population size must lie close to 400 . During the 7 -day period in 2003, we observed 155 events of dispersal between trees (Figure 3). For the most part (122 events) these concerned snails moved between neighbouring trees, although we also recorded movements to trees up to six trees apart. Of all dispersal events, 93 were by sinistral and 62 by dextral individuals. Hence, there was no significant difference in dispersal between the two morphs $\left(\chi^{2}=1.18 ; \mathrm{df}=1\right)$. Only one death (of a sinistral adult) was recorded. The second visit 1 year later, in 2004, yielded 62 living, marked individuals (21 juveniles and 41 adults). Of these, 24 were still on their original tree (ie, the last tree they were seen on the year before), whereas the remaining 38 had moved one, two, three, four, five, or six trees away $(18,11,5,2,1$, and 1 individuals, respectively; Figure 4).

Our per-tree population samples in 2003 ranged from 0 to 60 individuals. Using only the 25 trees in which 10 snails or more were present, we did not find any trees that were fixed for one morph. However, the proportions of dextrals ranged from 13 to $82 \%$ (Figure 5), and three trees showed significant deviation from expected $36 \%$ D: $64 \%$ S proportions (Table 1), but these did not remain significantly deviant after sequential Bonferroni correction.

\section{Discussion}

Our results suggest that the studied $A$. inversus population is well mixed. In just 7 days, a large proportion of the population at our study site was seen to move between trees, presumably via connected branches or the forest floor. Although dispersal was mostly limited to clusters of trees with strongly overlapping crowns, individuals were also seen to cross forest gaps. Over a whole year, almost two-thirds of the individuals had moved away from their original tree, in some cases travelling the length of the entire study plot. The generation time of Amphidromus is at least 2 years (MS, unpublished data). It is thus improbable that Amphidromus populations in separate trees in a closed forest will be sufficiently isolated for coiling morphs to become randomly fixed per tree. In our study locality, we found

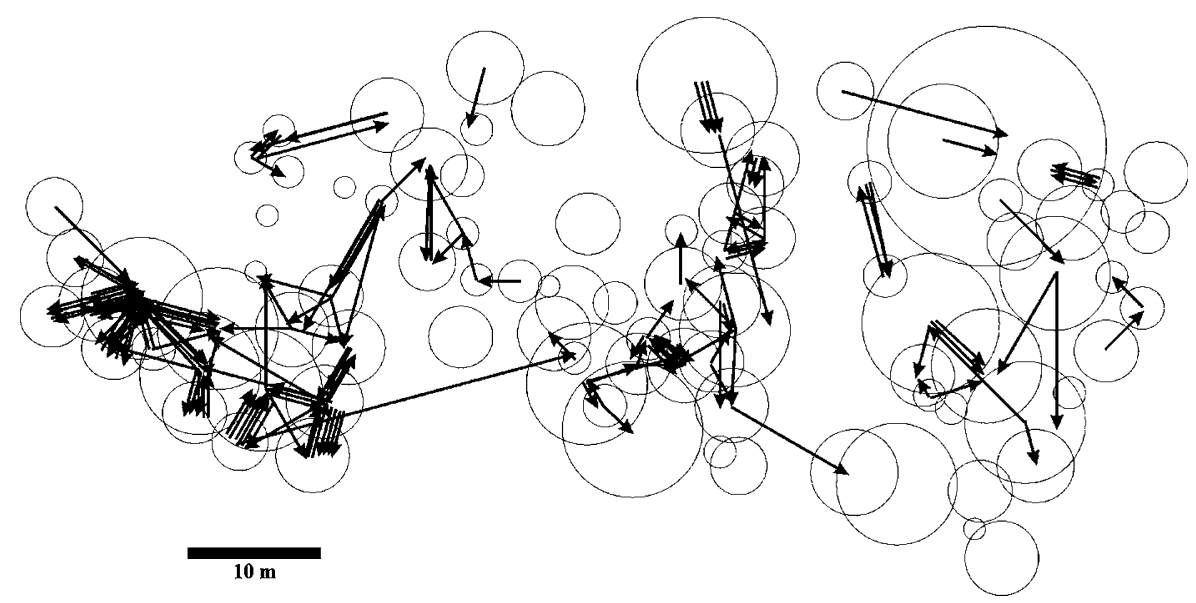

Figure 3 Map of the study site, with all observed dispersal events during a 7-day period in 2003 shown as arrows. 


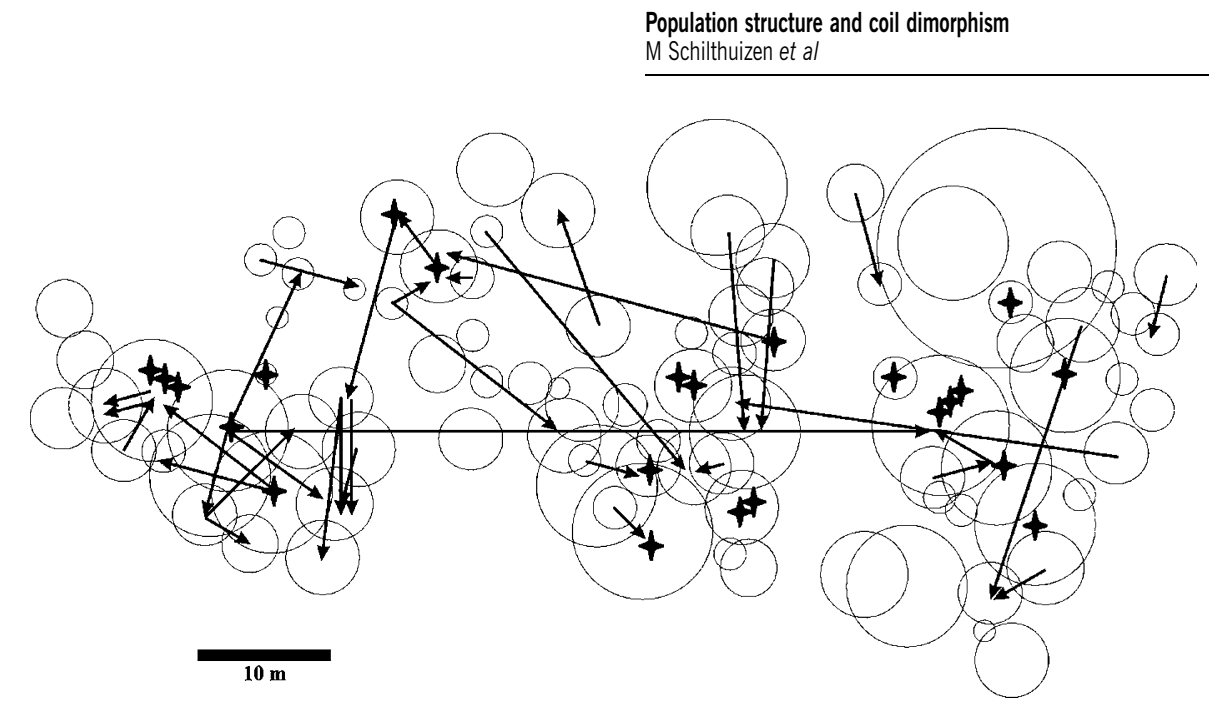

Figure 4 Map of the study site, with all observed dispersal events in a 1-year period shown as arrows. Stars indicate individuals that remained on their original tree.

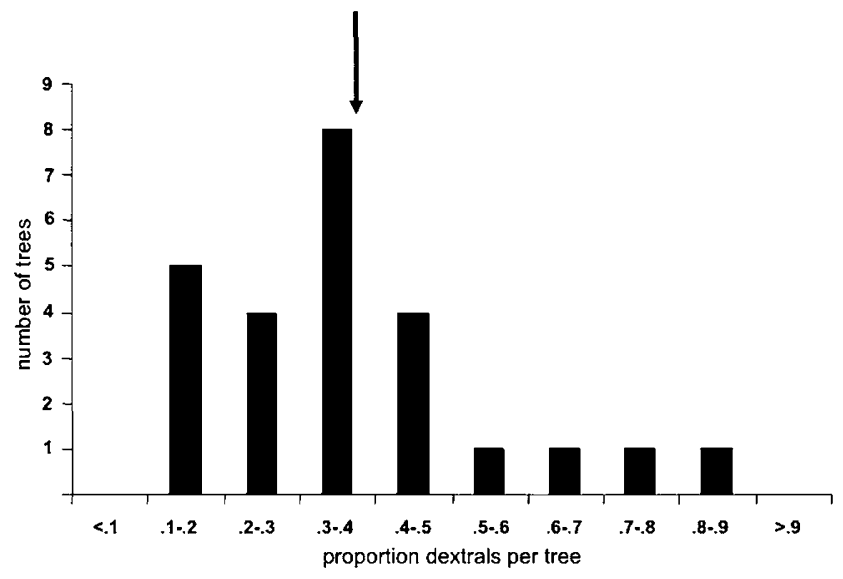

Figure 5 Distributions of proportions of dextrals per tree (only trees with $>9$ individuals included). The arrow indicates the average proportion of dextrals in the total population.

that all trees contained random samples of dextral and sinistral individuals, with no indication of bimodality.

We conclude that strong tree-level population structure is not present and is not a likely explanation for the maintenance of dimorphism. It is possible that our study site was not representative (for example, because of its relatively high population density), and tree-based populations are more strongly isolated elsewhere. However, spot checks at places in Kapas with lower population densities showed that trees with randomly mixed morphs are, in fact, the norm, and the same appears to apply to populations of $A$. martensi, a species from Borneo (MS and PGC, unpublished results). It is also possible that our study missed occasional longdistance dispersal to isolated, empty patches of habitat, which could subsequently become fixed for one coiling morph. However, in general, Amphidromus habitat consists of continuous closed-canopy forest, and such events will not be common.

If population structure alone cannot explain coil dimorphism, alternative hypotheses need to be sought. As we indicated above, very few 'exogenous' balancing factors are likely to be applicable to all dimorphic Amphidromus species. We suggest that further research
Table 1 Per-tree population censuses

\begin{tabular}{|c|c|c|c|c|c|}
\hline Tree & $\mathrm{N}_{o}(S)^{\mathrm{a}}$ & $\mathrm{N}_{o}(D)^{\mathrm{a}}$ & $\mathrm{N}_{o}^{\mathrm{a}}$ & $\mathrm{d}^{\mathrm{b}}$ & $\mathrm{P}^{\mathrm{c}}$ \\
\hline 1 & 3 & 10 & 13 & 0.77 & $0.006^{\circ}$ \\
\hline 2 & 13 & 6 & 19 & 0.32 & NS \\
\hline 3 & 11 & 3 & 14 & 0.21 & NS \\
\hline 6 & 2 & 9 & 11 & 0.82 & $0.006^{\circ}$ \\
\hline 9 & 8 & 7 & 15 & 0.47 & NS \\
\hline 10 & 14 & 7 & 21 & 0.33 & NS \\
\hline 13 & 31 & 29 & 60 & 0.48 & NS \\
\hline 15 & 8 & 2 & 10 & 0.20 & NS \\
\hline 18 & 7 & 3 & 10 & 0.30 & NS \\
\hline 25 & 11 & 5 & 16 & 0.31 & NS \\
\hline 31 & 8 & 3 & 11 & 0.27 & NS \\
\hline 34 & 15 & 3 & 18 & 0.17 & NS \\
\hline 44 & 12 & 9 & 21 & 0.43 & NS \\
\hline 46 & 12 & 7 & 19 & 0.37 & NS \\
\hline 48 & 17 & 9 & 26 & 0.35 & NS \\
\hline 52 & 4 & 7 & 11 & 0.64 & NS \\
\hline 55 & 13 & 2 & 15 & 0.13 & NS \\
\hline 58 & 10 & 6 & 16 & 0.38 & NS \\
\hline 60 & 6 & 9 & 15 & 0.60 & NS \\
\hline 67 & 12 & 6 & 18 & 0.33 & NS \\
\hline 71 & 8 & 4 & 12 & 0.33 & NS \\
\hline 73 & 8 & 2 & 10 & 0.20 & NS \\
\hline 77 & 13 & 13 & 26 & 0.50 & NS \\
\hline 78 & 11 & 3 & 14 & 0.21 & NS \\
\hline 88 & 19 & 3 & 22 & 0.14 & $0.04^{\mathrm{d}}$ \\
\hline
\end{tabular}

${ }^{a}$ Numbers of observed sinistral $\left(N_{\mathrm{o}}(\mathrm{S})\right)$ and dextral $\left(N_{\mathrm{o}}(\mathrm{D})\right)$ snails, with immigrants added, emigrants and deaths subtracted, and their $\operatorname{sum}\left(N_{\mathrm{o}}\right)$.

'Proportion of dextrals.

Significance of deviation from $36 \%$ dextrals in the entire population, using a two-tailed binomial test.

${ }^{\mathrm{d}}$ Not significant after sequential Bonferroni correction.

Only data for trees with $>9$ individuals have been presented.

investigate 'endogenous' factors, common to the entire subgenus. One possibly fruitful avenue would be to search for any advantages, rather than disadvantages, of interchiral copulation.

\section{Acknowledgements}

This study was financially supported by the Society for the Advancement of Research in the Tropics, Amsterdam (Treub Foundation) and a grant from Universiti Malaysia Sabah. The paper was greatly improved by comments 
from Edmund Gittenberger, Angus Davison, Takahiro Asami, and two anonymous reviewers.

\section{References}

Asami T (1993). Genetic variation and evolution of coiling chirality in snails. Forma 8: 263-276.

Asami T, Cowie RH, Ohbayashi K (1998). Evolution of mirror images by sexually asymmetric mating behavior in hermaphroditic snails. Am Nat 152: 225-236.

Ayala FJ, Campbell CA (1974). Frequency-dependent selection. Annu Rev Ecol Syst 5: 115-138.

Begon M (1979). Investigating Animal Abundance: CaptureRecapture for Biologists. Edward Arnold: Paris.

Degner E (1952). Der Erbgang der Inversion bei Laciniaria biplicata Mtg. Mitt Hamb Zool Mus Inst 51: 3-61.

Freeman G, Lundelius JW (1982). The developmental genetics of dextrality and sinistrality in the gastropod Lymnaea peregra. Wilhelm Roux's Arch Devel Biol 191: 69-83.

Giokas S, Mylonas M (2004). Dispersal patterns and population structure of the land snail Albinaria coerulea (Pulmonata: Clausiliidae). J Moll Stud 70: 107-116.

Gittenberger E (1988). Sympatric speciation in snails: a largely neglected model. Evolution 42: 826-828.

Holm S (1979). A simple sequentially rejective multiple test procedure. Scand J Stat 6: 65-70.

Johnson MS (1982). Polymorphism for direction of coil in Partula suturalis: behavioural isolation and positive frequency dependent selection. Heredity 49: 145-151.

Johnson MS, Clarke B, Murray J (1990). The coil polymorphism in Partula suturalis does not favor sympatric speciation. Evolution 44: 459-464.
Laidlaw FF, Solem A (1961). The land snail genus Amphidromus. A synoptic catalogue. Fieldiana Zool 41: 503-677.

Lehmann H, Maassen WJM (2004). A new species of Amphidromus from Laos (Gastropoda, Pulmonata, Camaenidae). Basteria 68: 17-20.

Mallet J (1986). Hybrid zones of Heliconius butterflies in Panama and the stability and movement of warning color clines. Heredity 56: 191-202.

Murray J, Clarke B (1976). Supergenes in polymorphic land snails. II. Partula suturalis. Heredity 37: 271-282.

Murray J, Clarke B (1984). Movement and gene flow in Partula taeniata. Malacologia 25: 343-348.

Orr HA (1991). Is single-gene speciation possible? Evolution 45: 764-769.

Panha S (1996). A new species of Amphidromus from Thailand. Malac Rev 29: 131-132.

Pfenninger M, Bahl A, Streit B (1996). Isolation by distance in a population of a small land snail Trochoidea geyeri: evidence from direct and indirect methods. Proc $R$ Soc Lond $B$ 263: 1211-1217.

Schilthuizen M, Lombaerts M (1994). Population structure and levels of gene flow in the Mediterranean land snail Albinaria corrugata (Pulmonata: Clausiliidae). Evolution 48: 577-586.

Stone J, Björklund M (2002). Delayed prezygotic isolating mechanisms: evolution with a twist. Proc $R$ Soc Lond $B$ 269: 861-865.

Ueshima R, Asami T (2003). Single-gene speciation by left-right reversal. Nature 425: 679 .

van Batenburg FHD, Gittenberger E (1996). Ease of fixation of a change in coiling: computer experiments on chirality in snails. Heredity 76: 278-286. 